\title{
La construcción de la patria por el discurso científico: México y Brasil (1770-1830)
}

\author{
Maria Rachel Fróes da Fonseca \\ CASA DE OSWALdo CRUZ-Fundación \\ OSWALDO CRUZ
}

\begin{abstract}
Se analiza la relación entre la afirmación de la práctica científica y la construcción de la idea de "patria" en el México

y en el Brasil coloniales. Se abarca la búsqueda de las principales expresiones del pensamiento científico en las obras de los mexicanos José Antonio Alzate (1738-1799) y José Ignacio Bartolache (1739-1790) y de los brasileños Manuel Arruda da Câmara (1752-1810) y Jacinto da Silva Quintão (?-1827) y el análisis de su significado en la constitución de la idea de "patria".
\end{abstract}

\section{INTRODUCCIÓN}

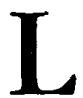

a recuperación de los antecedentes de la historia de la emancipación de América Latina por medio de ejemplos, y no de la política propiamente dicha, trae consigo una ampliación del enfoque analítico. En este estudio ${ }^{1}$ buscamos comprender

\footnotetext{
${ }^{1}$ Este artículo presenta algunos aspectos de mi tesis de doctorado "A única ciência é a Pátria: o discurso científico na construção do Brasil e do México (1770-1815)", Facultad de Filosofia, Letras y Ciencias Humanas-Universidad de São

Paulo, 1997.
}

de qué manera un grupo social, el de los científicos, comprendió el papel del conocimiento científico en la dirección y en el equilibrio de las principales cuestiones de la sociedad.

En realidad, se trata de destacar las principales expresiones del pensamiento científico y verificar su sentido en el proceso de toma de conciencia de la "patria". En términos más puntuales, se pretende detectar en la producción científica (memorias, ensayos, artículos) la forma en que es comprendida la ciencia en cuanto a su significado social. El objetivo es percibir cómo ciertas prácticas y valores son resalta- 
dos como señales de reconocimiento de la realidad en la cual están insertos.

En el análisis de estos discursos podremos percibir cuál es el sentido conferido a los términos "patria" y "patriota". De esta manera, se puede aquilatar la correlación entre la práctica científica y la formulación de presupuestos ideológicos a partir del pensamiento de los mexicanos José Antonio Alzate y José Ignacio Bartolache, ilustrados de formación enciclopedista, y de los brasileños Jacinto José da Silva Quintāo y Manuel Arruda da Câmara.

En sus ideas científicas procuraremos destacar en qué forma conciben la ciencia, sus elementos y la aplicación de los conocimientos científicos al equilibrio de los problemas vividos por sus sociedades.

Los científicos, de acuerdo con el dominio colonial en el que estaban insertos, encontraron distintos espacios y vehículos de divulgación del saber científico. Por una parte, la creación de asociaciones y de agremiaciones científicas y/o literarias, que fueron importantes espacios para el debate de los conocimientos científicos en boga y para la evaluación de su aplicabilidad en tierras americanas. Asociaciones, como la brasileña Sociedade Literária do Rio de Janeiro, características del movimiento de la Ilustración, privilegiaban la investigación científica de la naturaleza, la divulgación del saber y su utilidad para aquellas sociedades.

En la formulación de estos conocimientos científicos fue decisivo el impacto de las teorías de inferioridad y de inmadurez conferidas a la naturaleza americana, en la segunda mitad del siglo XVIII, por pensadores europeos como Buffon y De Pauw. Esas teorías tenían como pauta la tendencia de la época, o sea, la afirmación de una estrecha conexión orgánica del ser vivo con la naturaleza de un modo determinista. Ilustrados americanos procuraron responder a estas afirmaciones, a estas "calumnias", como ellos afirmaban, estimulando la producción de conocimientos que derrumbasen aquellas visiones despectivas del continente americano. Lo que importaba era resaltar más que nunca las potencialidades y las virtudes de aquella naturaleza. Los estudios deberían expresar no sólo las descripciones físicas de aquellas tierras, sino también su potencial económico y humano.

\section{LA POLÉMICA SOBRE LA NATURALEZA} AMERICANA

La naturaleza americana fue objeto de constantes reflexiones y juicios por parte de pensadores europeos desde el momento del "descubrimiento" 2 de las tierras del nuevo mundo. Los relatos de los viajes de Colón, entre otros, son testimonios significativos de la visión europea sobre América. En esta concepción, aquellas tierras existían solamente a partir de la significación

\footnotetext{
${ }^{2}$ El término descubrimiento aparece entrecomillado para reafirmar nuestra visión de este hecho histórico. Corroboramos de esta manera la visión de Edmundo O'Gorman, Invenção, 1992, según la cual América fue inventada antes de ser descubierta. Por otro lado, la idea de descubrimiento presupone la ausencia de cualquier existencia social anterior, lo cual negaria la presencia y el valor de las antiguas civilizaciones en el continente americano.
} 


\section{SECUENCIA}

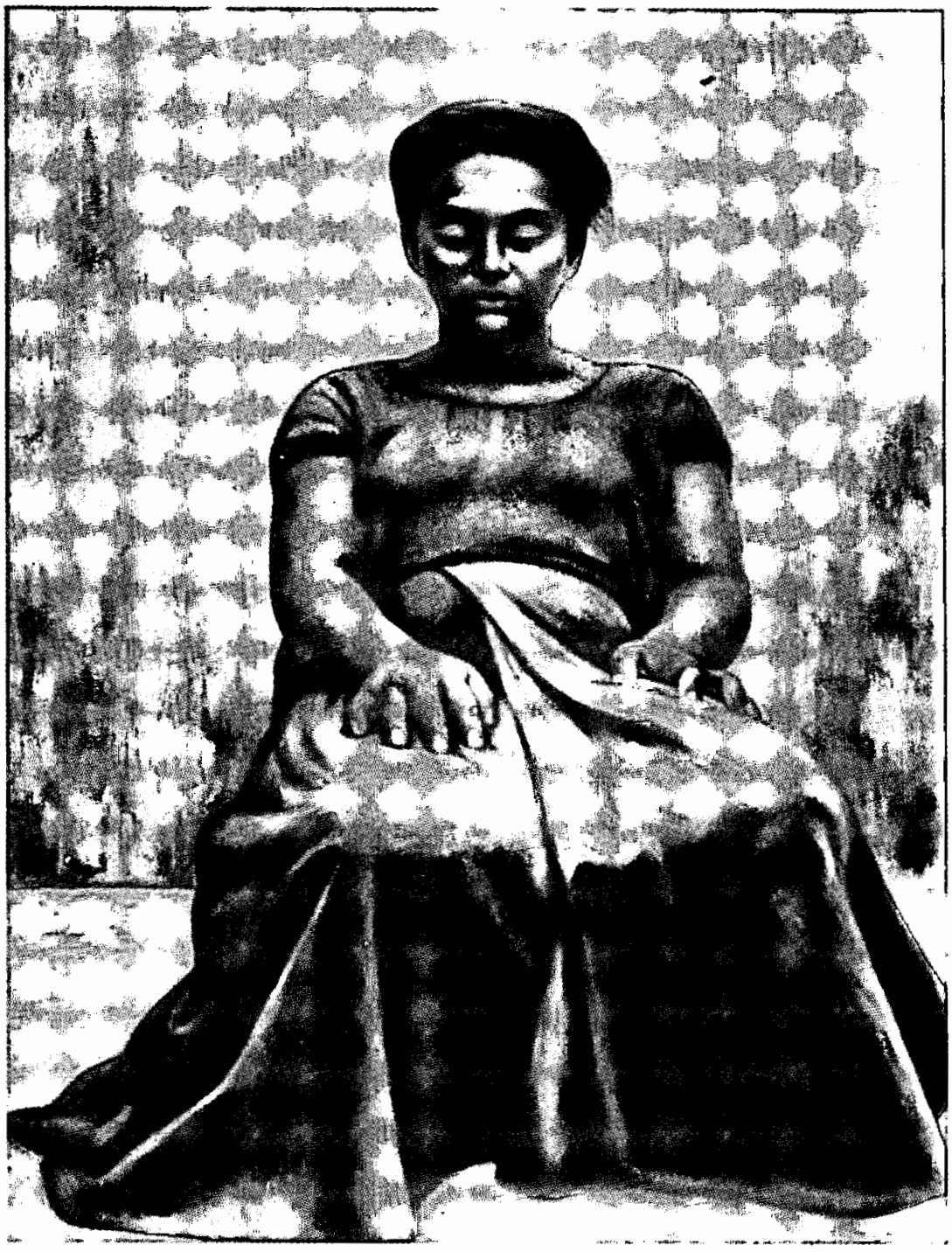


que les era conferida por sus "descubridores", según los deseos y sueños de éstos. Así se determinaba la existencia de un vacío sociocultural en el nuevo mundo, mundo que sólo podía ser comprendido según los atributos que le fueran previamente otorgados por el imaginario europeo.

Posteriormente, con el proceso de colonización, con la necesidad de adecuar aquellos territorios a los objetivos e intereses de las metrópolis europeas, la concepción sobre aquella naturaleza y sus ocupantes se transformó radicalmente. Viajeros, funcionarios reales y religiosos prosiguieron en la identificación y caracterización de aquellos dominios; no obstante, gran parte de sus relatos, como los del padre Acosta (1590), de Antonio Herrera (1601) y del padre Cobo (1653), los describían aún de manera bastante negativa. Estos textos eran reflexiones y observaciones, y no constituían teorías sobre la naturaleza americana.

La segunda mitad del siglo XviI fue el periodo característico en la formulación de concepciones sobre las tierras americanas, el contexto de las teorías de inferioridad y de inmadurez de la naturaleza americana, elaboradas por los europeos Buffon, De Pauw y Raynal. La polémica sobre la naturaleza americana adquiere otras dimensiones en este momento, teniendo en cuenta la simultaneidad entre la plenitud del proceso de concientización de la propia Europa y el nacimiento del orgullo y el patriotismo en las zonas coloniales de América.

Estos pensadores eran representantes de una tendencia vigente entonces, la de la conexión orgánica del ser vivo con la naturaleza, fijando relaciones bastante deterministas.

El naturalista George-Louis Leclerc, conde de Buffon (1707-1788), afirmaba que el continente americano era, geológicamente, más joven, presentando por ello una abundancia de ríos y lagos, constituyéndose en un ambiente muy frío y húmedo, inhóspito para el pleno desarrollo de la naturaleza viva. Guillaume-Thomas Raynal (1713-1796) caracterizó al criollo ${ }^{3}$ como un ser indolente, indiferente, con vicios, características derivadas de las condiciones climáticas.

Una obra posterior, Recherches philosopbiques sur les américains (1771), del clérigo prusiano Cornelius De Pauw, desarrolló los argumentos de Buffon radicalizándolos y contemplando no sólo la fauna, sino concentrando la atención y los ataques en los hombres americanos, que son definidos como naturalmente brutos, salvajes y primitivos. Afirmaciones como éstas provocaron las reacciones más incisivas, "reavivando" la polémica, en la medida en que la capacidad americana no sólo era puesta en entredicho, sino que se determinaba la naturalidad y la inmutabilidad de esta inferioridad. La causalidad natural confería a aquella inferioridad un carácter perenne, presupuesto

\footnotetext{
${ }^{3}$ El término criollo se refiere al habitante de descendencia española, pero nacido ya en las colonias de la América española. Optamos por representarlo en la grafía española y subrayado en el original en portugués para destacarlo, teniendo en cuenta el desvirtuamiento de su sentido cuando se traduce al portugués (En la traducción al español, criollo se mantiene sin subrayar $\mathrm{N}$. de la $\mathrm{T}$.)
} 
adecuado para el mantenimiento de un tutelaje político.

En su primera etapa, la polémica sobre el continente americano se desarrolló principalmente en torno a cuestiones de naturaleza zoológica, etnográfica y climatológica. En otros contextos, cuando se esbozaba la afirmación política en América a través de los movimientos de independencia de las colonias (el caso de las colonias inglesas era ejemplar), al pensamiento europeo le importaba buscar los cánones por los cuales el continente americano se insertaría en la historia occidental. El enriquecimiento de la dimensión política de la discusión también se debió al involucramiento de los jesuitas expulsados (1767) de América y deportados a Europa. De esta forma, la polémica se recondujo y amplió, aventajando las cuestiones políticas a las científicas que habían motivado a Buffon.

Atributos como la estupidez, la inercia, la ignorancia y la cobardía se aplicaban a todos los americanos, incluyendo los criollos, cuya incapacidad los sentenciaba a permanecer eternamente sometidos políticamente a otro pueblo.

El antagonismo entre criollos y europeos, y más específicamente los espanooles, existió desde las primeras décadas de la presencia española en América. Esta diferenciación no era inicialmente, económica o social, sino geográfica, esto es, en función del lugar de nacimiento. Aquel que nacía en las Indias estaba necesariamente subordinado a los peninsulares, con los que tenía varios rasgos en común (color de la piel, religión, lengua...). La ascensión a cargos altos en la administración civil o eclesiástica les estaba vetada.
Este antagonismo se exacerbó en la segunda mitad del siglo XVIII, cuando las condiciones coloniales y las reformas puestas en práctica por la corona española intensificaron las discriminaciones y las restricciones de incorporación del criollo.

Este criollo, despreciado por el europeo tanto en suelo americano como en los foros intelectuales del viejo continente, buscará su espacio y su identidad. El nacimiento de sentimientos "patrióticos" se va a dar como forma de reflexión y de reacción a las posiciones de los pensadores europeos. El retorno a la historia del pasado americano a través de la descripción de las costumbres y de las realizaciones de las primeras civilizaciones, y el reconocimiento de las conquistas culturales y sociales de los americanos en aquel momento, constituyeron elementos para afirmar su orgullo ante el pensamiento europeo.

Los primeros esfuerzos en este sentido buscaban la identificación de los recursos vegetales y minerales, de las peculiaridades, de la fauna y de la flora americanas. La presencia de recursos, como la abundancia de oro y de plata, les parecía argumento irrefutable de la positividad del suelo americano. La producción de obras como la Biblioteca mexicana de Eguiara y Eguren, representó uno de los primeros instrumentos de afirmación de las dotes intelectuales de aquellos hombres a los que se llamaba brutos. Posteriormente, otros americanos como Clavijero, José Antonio Alzate y José Ignacio Bartolache (México), Hipólito Unánue (Perú), Francisco José de Caldas (Colombia), Jacinto José da Silva Quintão y 
Manuel Arruda Câmara (Brasil), representantes de la Ilustración, buscaron igualmente el conocimiento de las potencialidades, de las virtudes y de los beneficios de sus tierras.

\section{El CONTEXTO DE LA ILUSTRACiÓN}

El siglo XVIII despertó a la naturaleza como el momento para su conocimiento y dominio y ya no simplemente para su contemplación. Se afirmaba el poder de la Razón, la idea de felicidad y de progreso a la luz del conocimiento de las ciencias.

La ciencia era vista como un importante agente de transformación del mundo, y pasó a ser comprendida a través de una nueva concepción secular, abandonándose la antigua concepción religiosa. Entre los saberes científicos se privilegiaba a las ciencias naturales y su método de conocimiento. Se daba prioridad a la enseñanza y divulgación de las ideas científicas modernas y al establecimiento de espacios para el debate científico. Los campos que se desarrollaron, como la botánica, la geografía y la química, fueron innumerables.

En este movimiento de renovación, las llamadas ciencias aplicadas despertaron gran interés, sobre todo la agricultura, la minería y la metalurgia, consideradas como "conocimientos útiles" que proporcionaron el instrumental teórico (conceptos, modelos y procedimientos) y práctico (instrumentos, aparatos) para una mejor utilización de los recursos de cada región.

La institucionalización de esta práctica científica se procesó de varias for- mas, a través de la fundación de instituciones de enseñanza e investigación, de la creación de periódicos para la divulgación científica y de la revisión del currículum científico. El movimiento de la Ilustración no se constituyó en una única forma de pensar ni en una única propuesta de cambio, como bien lo destacó M. De Lourdes Lyra, ${ }^{4}$ sino que se expresó con algunas especificidades en contextos distintos.

En Nueva España, este movimiento de renovación cultural se compone de las principales ideas ilustradas: lucha contra la tradición escolástica, idea de progreso, utilidad de la ciencia, racionalismo, eclecticismo, uso de procedimientos experimentales, el enciclopedismo y sus divulgadores. Las ciencias empezaron a recibir una orientación más práctica, principalmente en lo que se refiere a la veterinaria, la botánica y la medicina. La astronomía y las matemáticas gozaron de grandes progresos, y hubo expresiones como la de Carlos de Sigüenza y Góngora. La intelectualidad, con una presencia más dinámica en este proceso, se involucró con la adopción de estas nuevas prácticas científicas, como lo prueban los textos de sor Juana Inés de la Cruz (poetisa, intelectual).

El ilustrado mexicano buscó realizar un gran inventario de la riqueza material y cultural mexicanas, elaborando estudios sobre su naturaleza y divulgando los conocimientos más útiles a aquella sociedad. El carácter utilitario de la ciencia es lo que le confería su fundamento. En este movimiento, se destacaron José Antonio Alzate y José

\footnotetext{
${ }^{4}$ Lyra, Utopia, 1994, p. 32.
} 
Ignacio Bartolache, cuyas trayectorias priorizaron los procedimientos y los instrumentos científicos, estableciendo nuevos conocimientos, intermediando en el paso de la ciencia tradicional a la ciencia moderna. A partir de la se. gunda mitad del siglo XVU, la difusión y la enseñanza de corrientes científicas modernas se intensificaron con el surgimiento, en la capital mexicana, de diversas publicaciones científicas especializadas y no especializadas, destacándose los periódicos éditados por Alzate y por Bartolache ${ }^{6}$

La acción del despotismo ilustrado de Carlos III, inserta en una política de explotación más racional de los recur. sos coloniales, propició a su vez el incremento en la entonces colonia española de diversas áreas de conocimiento a través de la creación de instituciones de enseñanza e investigación, como el Real Seminario de Minería, el Jardín Botánico y la Real Escuela de Cirugía. Otras medidas del gobierno español, como la realización de expediciones (geográficas, botánicas y médico-sanitarias) contribuirían igualmente a este movimiento de renovación científica novohispano.

La comparación de la Ilustración en Brasil con la de otras regiones del continente americano suscitó, como bien lo señaló Francisco Falcon, ${ }^{7}$ una serie de discrepancias en cuanto a la evaluación del movimiento en la América portuguesa. Por una parte, se afirmó no sólo la diferencia de la vida intelectual

\footnotetext{
${ }^{5}$ Alzate, Asuntos, 1772; Diario, 1768; Gacetas, 1831

${ }^{6}$ Bartolache, Mercurio, 1772.

7Falcon, "Ilustração", 1989.
}

desarrollada en estas regiones, sino que también se llegó a cuestionar la existencia de tal movimiento en Brasil.

Desde nuestra perspectiva se ponen de manifiesto innumerables aspectos que pueden servir como parámetros para una contemplación comparativa del movimiento ilustrado en el virreinato de Nueva España y en la colonia de Brasil. Uno de estos parámetros sería la política reformista adoptada por los gobiernos metropolitanos y su influencia en el desarrollo científico y cultural de las colonias. Podemos constatar que existían diferencias entre el reformismo del gobierno español y el emprendido por la metrópoli portuguesa.

Como señalamos anteriormente, el gobierno español adoptó una serie de medidas de fomento, cuyo impacto se puede medir por el carácter histórico de las instituciones de enseñanza y de investigación creadas en este contexto y por el significado de las diversas expediciones científicas para la institucionalización de la práctica científica moderna. La nueva política ilustrada de los Borbones se caracterizó fundamentalmente por la busqueda del control racional de las colonias americanas por medio de una nueva estructura administrativa y de una reforma de carácter científico.

Por otro lado, el reformismo portugués, a pesar de que también dirigía una política de fomento de la economía colonial para la recuperación de la metrópoli portuguesa, no desencadenó el mismo cuadro favorable para el desarrollo de la práctica científica en sus dominios ultramarinos. La política de fomento puesta en práctica a partir de 1770 a través de las administra- 
ciones de los virreyes (marqués do Lavradio, Luis de Vasconcelos e Sousa) fue más tímida, y consistia básicamente en el trasplante de especies botánicas al país, introduciendo y estimulando cultivos considerados importantes en términos económicos como el añil, la cochinilla y el lino. Para ello, se propuso la creación de jardines botánicos para la aclimatación y el conocimiento de las especies, la realización de investigaciones de campo en varias capitanías, y la elaboración de tesis de botánica económica. Para el incremento de la minería se incentivó la realización de análisis de muestras de minas. Esta política desarrollista se consolidó con el apoyo a asociaciones como la Academia Científica y la Sociedad Literaria de Río de Janeiro -en las cuales participaban el botánico Manuel Arruda da Câmara y el médico Jacinto José da Silva Quintão-, pero no creó las mismas condiciones puestas en práctica por el gobierno español para la promoción del desarrollo científico.

Esta diferente recepción del movimiento de la Ilustración en los dominios coloniales portugués y español ha sido atribuida ${ }^{8}$ a que este movimiento había obtenido mayor espacio en la metrópoli española que en la portuguesa y, por consiguiente, sus colonias habían parecido más fértiles para las ideas ilustradas. Constatamos la presencia de los conceptos más representativos de la Ilustración, como la creencia en el poder de la razón, el conocimiento de la naturaleza y la idea de felicidad y de progreso también en el Brasil colonial del siglo XvIU.

${ }^{8}$ Whitaker, "Dual", 1942.
Los ilustrados brasileños preconizaban a través de sus estudios el conocimiento de la naturaleza brasileña y el desarrollo de los conocimientos útiles, imbuidos de una visión pragmática de la ciencia. La historia natural y sus ramas atraían el interés de estudiosos, destacándose los importantes trabajos de botánica, en los que este conocimiento se presentaba relacionado con otras áreas como la medicina, la agricultura y la química. Nuevos experimentos, nuevos procedimientos y técnicas también fueron propuestos para el fundamento de otras ciencias, como la mineralogía y las matemáticas.

También es importante señalar otra dimensión del movimiento de la Ilustración en Brasil, la dimensión social. Nos referimos a la existencia de un antagonismo entre los llamados "blancos nacionales" o "mazombos", y los portugueses o "reinóis" que, aunque antiguo, se encontraba exacerbado en aquel momento. Los blancos nacionales formaban "el cuerpo de la nación", ${ }^{10}$ pero estaban excluidos de los principales cargos de la administración colonial. Entre estos "blancos nacionales" se encontraban los letrados, los hombres de letras en la expresión de la época. De esta forma, este sentimiento de exclusión compartido por éstos fue un factor más en el proceso de construcción del conocimiento científico.

En el transcurso de la afirmación de las nuevas ideas científicas, en el despertar de la preocupación por la natu-

\footnotetext{
${ }^{9}$ El término mazombo, de carácter despectivo, se atribuía al hijo de europeos, especialmente portugueses, nacido en Brasil.

10 "Idéias", 1884, pp. 127-128.
} 


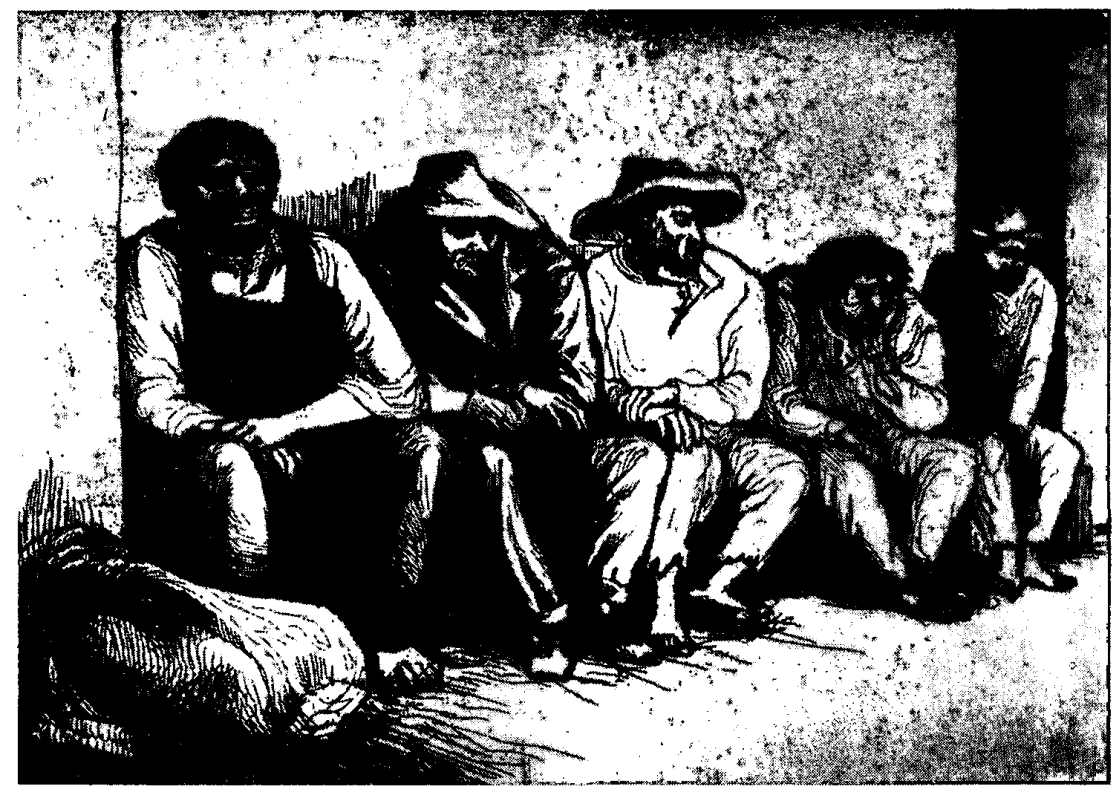

raleza, los ilustrados mexicanos y brasileños expresaban como misión su interés por servir a la "patria". Alzate, Bartolache, Arruda da Câmara y Jacinto Quintao, a través de los periódicos y de estudios, esbozaban sus ideas sobre la "nación" que empezaban a "imaginar".

LA CONSTRUCCIÓN DE LA "NACIONALIDAD" MEXICANA: JOSÉ ANTONIO AIZATE Y JOSÉ IGNACIO BARTOLACHE

La obra de José Antonio Alzate y Ramírez (1737, Ozumba, Nueva España; 1799, México) se caracterizó por su espíritu ilustrado, por el énfasis en el conocimiento científico, por la actitud racionalista, por la evidencia de los métodos científicos, por la idea de difusión y por el carácter enciclopédico de los temas que abordó.

En su concepción de la ciencia, el dominio sobre la naturaleza se comprendía como el camino para alcanzar la felicidad de la sociedad a través de la utilización de los conocimientos científicos, en especial de las disciplinas naturales.

Las obras de Alzate exponen algunas reflexiones sobre el conocimiento científico, pero no constituyen una doctrina concebida de manera armónica y sistemática. Él no buscaba reflexionar sobre el proceso de construcción del saber científico, pero sí proponer una 
comprensión sobre la realidad mexicana bajo la perspectiva de los nuevos conocimientos. El interés científico estaba presente, pero sometido al deseo de mostrar los recursos de las tierras mexicanas y de buscar los medios adecuados para aprovecharlos. Su vocación científica era comprendida como una misión, la de llevar la verdadera ciencia a todos para que la desarrollaran en su beneficio.

El conocimiento útil era el realmente verdadero, puesto que la noción de utilidad era la que definía a la ciencia en la visión alzatiana. Su definición, característica del movimiento de la Ilustración, se basaba en la negación de su carácter meramente especulativo y abstracto, afirmando en contrapartida su aspecto práctico. Entendía por ciencia útil el conjunto de materias que solucionaban o que encaminaban soluciones para los problemas económicos y sociales del país, haciendo posible la solución de los mismos. En este sentido orientó sus estudios, procurando abordar aspectos importantes para el desarrollo de la medicina, de la agricultura, de la minería, de la botánica, de la física, de la arquitectura, de la geografía y de la astronomía, como conocimientos científicos capaces de abordar problemas como la pobreza, las dolencias, etcétera.

Alzate, como otros ilustrados mexicanos, no fue sordo a los escritores europeos, y se propuso cuestionar las posiciones de éstos sobre el continente americano, especialmente las injurias e incorrecciones de De Pauw y de la Enciclopedia.

A la máxima de De Pauw sobre la incapacidad intelectual de los novohis- panos, nuestro científico criollo replicaba trazando algunos aspectos de la vida cultural que éstos desarrollaban:

pero si vuestra merced no tuviese lagañas, si $[\ldots]$ vería que México es una de las ciudades principales del orbe; vería que la literatura no se halla tan atrasada, porque tanto libro que se conduce, como consta en las Gacetas, diez o más librerías ia quién surten?, ¿a los apaches o calmucos? ¿Ha visto vuestra merced que alguna cátedra permanezca vacante en la Real Universidad y colegios de enseñanza por falta de sujetos? ¿Ignora vuestra merced que para un concurso u oposiciones a curatos se presentan centenares? ¿No se cuentan en sólo México más de 200 abogados? ¿El número de médicos no es el suficiente, sino sobrado? [...] ¿Pero pasaré en silencio que se hallan muchos aplicados a las matemáticas, a la física experimental, etcétera, etcétera? [...] ¿Y el que se dedica aquí a las ciencias naturales a qué puede aspirar? ${ }^{11}$

El ilustrado mexicano refutaba a De Pauw, apuntando las virtudes de las especies animales y vegetales, y la riqueza de los minerales, buscando inferir que en América, por una concordante analógica, las manos supremas depositaron en sus tierras muchos de los recursos encontrados en el mundo antiguo, como también le reservaron algunas maravillas.

El reconocimiento de las potencialidades naturales representaba uno de los caminos para la creación y afirmación de la conciencia de la nacionali-

${ }^{11}$ Alzate, "Respuesta", 1989, pp. 112-114. 
dad. Además, era importante conferir a aquella comunidad un pasado que le fuese propio. La defensa de los antiguos mexicanos, del pasado azteca, era de gran significación en este proceso, puesto que la presencia colonial, con sus prerrogativas, los había privado de su historia.

La observación y la experimentación conducían los esfuerzos de los científicos criollos, como Alzate, en busca de una ciencia propia en la tierra americana. Defendía a los de su tiempo y a los antiguos, que le conferían un pasado, una historia y, por tanto, su existencia. Forjaba la cultura criolla y la nueva "patria".

El debate en relación con el verdadero conocedor de la naturaleza de las tierras americanas representó uno de los factores desencadenantes de la construcción de la conciencia "nacional" en Nueva España. Este movimiento adquirió un rumbo especial con la polémica sobre la naturaleza americana. Los desbordamientos de aquella polémica conducirían a un cuestionamiento de la relación de la colonia con la metrópoli.

Aunque José Antonio Alzate y Ramírez no se hubiera propuesto en momento alguno la separación política de la colonia en relación con la metrópoli, contribuyó efectivamente a la construcción del orgullo criollo, fomentando una conciencia mexicana. La mexicanidad se comprendía en la exaltación de la naturaleza y de su hombre, en la afirmación de sus peculiaridades y en el conocimiento de sí y de su tierra: "Mi amor a la patria, amor que me obligaría a sacrificar mi vida, si fuese necesario, es el que me ha obli- gado y obliga aún a continuar en mi primer empeño."12

La ciencia por sí misma no haría surgir al país, pero permitiría capacitarlo a través del descubrimiento de recursos para su crecimiento futuro. Por otro lado, el desarrollo de las investigaciones científicas, pautadas en procedimientos de la ciencia moderna, su divulgación entre los sectores sociales y su aplicación en beneficio de aquella sociedad, significarían etapas fundamentales para el engrandecimiento de la "patria". Significaba la posibilidad de una ciencia propia, o mejor, de un saber científico construido según condiciones peculiares de la realidad americana. Buscaba, por la defensa de la cultura, la construcción de la "nación".

La orientación de José Bartolache y Díaz de Posadas (1739, Guanajuato1790, Nueva España) se manifestó en su propósito de difundir y popularizar a la ciencia, destacando los conocimientos médicos (nuevos medicamentos, nuevas terapias, renovación de la enseñanza médica). Combatió la tradición, proponiendo una nueva visión filosófica y científica, pautada fundamentalmente por la noción del conocimiento cierto logrado a través de los caminos seguros del saber, el método científico. El conocimiento científico ofrecía también un significado social al fomentar la construcción y la afirmación de valores constitutivos de la patria.

De manera semejante a Alzate, el médico José Ignacio Bartolache apuntaba al significado social del conocimiento científico como un instrumen-

${ }^{12}$ Alzate, Gaceta, 1788-1790, p. 419. 
to para la construcción y la afirmación de valores constitutivos de la idea de una comunidad política, de la patria. La distinción nación y patria correspondía a dos sentimientos de pertenencia, el primero a la monarquía española y el segundo al lugar de nacimiento.

Su principal objetivo era el de "ser útil a la nación y a la patria"13 y en esta perspectiva privilegiaba los estudios que más beneficios y más curiosidad produjesen en "nuestros americanos". ${ }^{14}$ Su periódico Mercurio Volante con Noticias Importantes y Curiosas sobre Varios Asuntos de Física y Medicina, aunque centrado en el conocimiento de la medicina, se dedicó también a otras temáticas en una perspectiva más amplia del conocimiento científico.

Daba crédito de la riqueza natural de "Nuestra América Septentrional", pero tenía claridad en cuanto al hecho de que, en términos culturales, Nueva España no presentaba aún el mismo florecimiento presente en otras regiones. Este desfase era producto, en la visión del médico, de cuestiones circunstanciales, como los pocos años de historia de aquel virreinato, insuficientes para la realización de grandes progresos. Su apreciación no tenía por resultado la negación de la existencia de novohispanos admirables y capacitados para aprender conocimientos importantes.

${ }^{13}$ Bartolache y Díaz de Posada, José Ignacio, Mercurio Volante con Noticias Importantes y Curiosas sobre Varios Asuntos de Física y Medicina, núm. 8, 9 de diciembre de 1772 .

${ }^{14}$ Ibid., núm. 16, 10 de febrero de 1772.
En la perspectiva utilitarista de la ciencia, los conocimientos útiles eran objeto constante de sus reflexiones, incluyendo la proposición de terapias, la descripción del instrumental médico (el termómetro, el barómetro), discusiones sobre patologías y sobre disciplinas médicas, observaciones de física y de astronomía.

Paralelamente a su formación en medicina, Bartolache dedicó también gran parte de su tiempo a la reflexión de las matemáticas bajo la dirección de otro ilustrado, Joaquín Velázquez de León (minerálogo), de donde resultó la elaboración de la obra Lecciones de matemáticas,${ }^{15}$ un cuaderno sobre matemáticas modernas.

A través de la adopción de los principios y valores de la ciencia moderna proponía no sólo la renovación, sino también el enriquecimiento de los conocimientos sobre la tierra mexicana. Se rebeló contra la forma tradicional de ciencia adoptada en la universidad mexicana y buscó escribir para los suyos, para su patria, exaltando su naturaleza y reconociendo sus necesidades. Se estaba configurando una nueva cultura para una nueva patria.

\section{LA NATURALEZA BRASILEÑA POR "BRASILEÑOS": MANUEL ARRUdDA Câmara Y JaCinTo JosÉ DA SILVA Quintão}

Igualmente movidos por la búsqueda y por la afirmación del conocimiento de la naturaleza, Manuel Arruda da Câmara y Jacinto José da Silva Quintão, en

${ }^{15}$ Bartolache, Lecciones, 1769. 


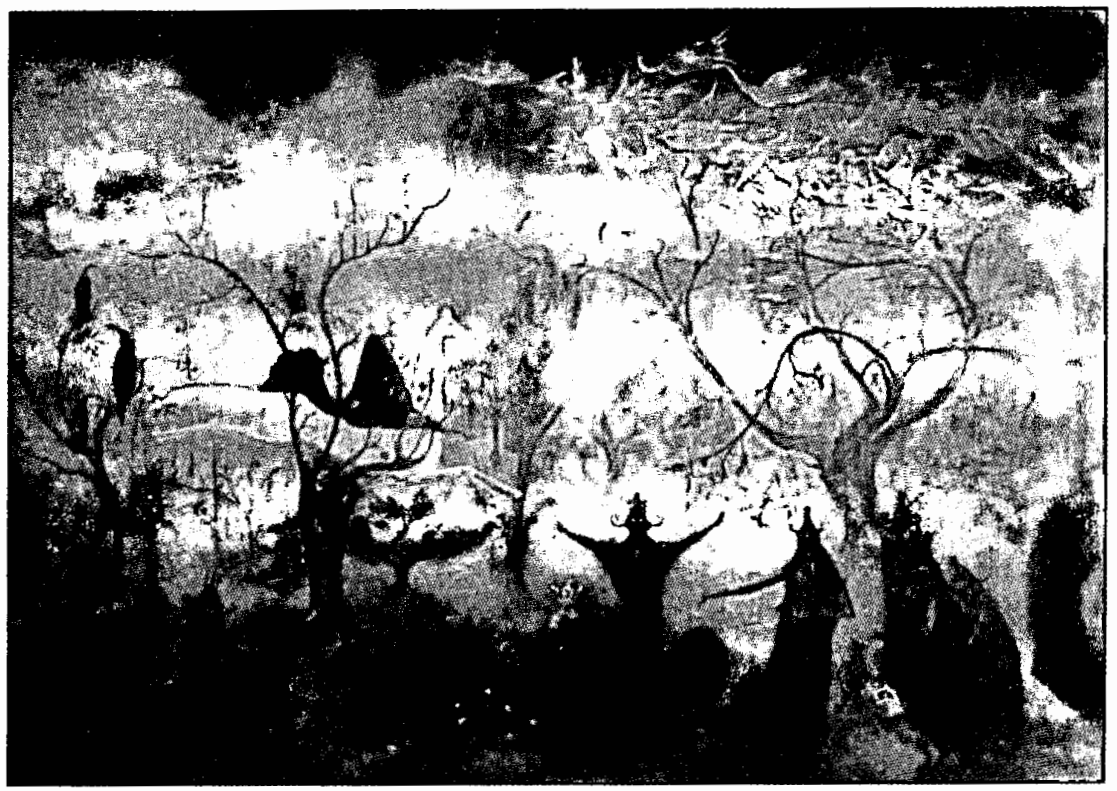

Brasil, procuraron difundir los "conocimientos útiles", entendidos como aquellos que realmente representasen un beneficio público. Las ideas de prosperidad pública y de engrandecimiento de la patria estuvieron presentes en sus estudios, principalmente a través del estudio de nuevos cultivos, nuevos medicamentos y nuevas técnicas.

Manuel Arruda da Câmara (1752, Vila de Pombal. Paraíba, Brasil, 1810, Pernambuco, Brasil), en sus estudios y memorias, afirmaba la importancia de la ciencia y su utilidad para el crecimiento del país. El conocimiento debería estar fundamentado en la experiencia, el único lenguaje posible y decisivo. Las reflexiones teóricas de los "soñadores de gabinete"16 representaban un tiempo perdido, puesto que no influirían en el crecimiento de la riqueza del país.

Arruda da Câmara concebía el conocimiento y el dominio de la naturaleza como tareas fundamentales para la promoción de la felicidad pública. De la naturaleza se extraerían todos los recursos para el sustento y la sobrevivencia de los hombres. El reino vegetal, como se refería, era en la más pura concepción de la Ilustración del siglo XVIII, la fuente más importante de riquezas de cualquier nación y, por tan-

${ }^{16}$ Câmara, "Memória", 1982, p. 253. 
to, había llegado el momento de su conocimiento y de su producción.

En este sentido elaboró innumerables tesis que versaban sobre los diversos vegetales existentes en las tierras brasileñas, destacando especialmente aquellos cuya explotación representaría resultados económicos, tales como los que proporcionaban aceites, lino, vino, féculas, harinas, frutas y medicamentos.

Se hizo notable por sus estudios sobre diversos cultivos, especialmente sobre el de los algodoneros, discurriendo acerca del proceso para su introducción en el país, su potencial económico, la descripción de sus diferentes especies, sus condiciones de plantío y los métodos más adecuados.

La afirmación de la naturalidad de las especies era un punto fundamental en su esfuerzo de caracterización de las especificidades de la naturaleza brasileña, cuestión central para estos científicos, porque "la naturaleza dio a cada país, o a cada clima, sus privilegios exclusivos, y siempre los gozarán a pesar de todo esfuerzo de arte". ${ }^{17}$

Las tierras brasileñas presentaban peculiaridades que no podían ser despreciadas, puesto que eran específicamente estas propiedades las que las distinguían y les conferían una existencia rica. Destacaba además que las características naturales brasileñas eran las más adecuadas para el cultivo en cuestión:

En este país no se distinguen, como en Europa, las cuatro estaciones constantes, apenas se marcan dos, verano e in-

${ }^{17}$ Ibid., p. 48. vierno $[\ldots]$. Donde no hay esta multiplicidad de sierras y los campos son más espaciosos, las lluvias no son tantas, la temperatura del aire es seca y caliente, lo llaman fértil. Éste es el clima más conveniente para la plantación del algodón; allí crece bien, produce abundantemente, con tal de que se escoja la tierra, lo cual recomendé en el capítulo precedente, allí finalmente dura el algodonero diez, doce, catorce y más años. ${ }^{18}$

El conocimiento de la naturaleza brasileña no sólo representaba la posibilidad de su explotación económica, también proporcionaba un conjunto de enseñanzas para la ciencia médica a través de la constatación de la propiedad medicinal de innumerables plantas brasileñas. Corroborando el pragmatismo científico en boga, afirmaba que el conocimiento científico debería necesariamente tener como parámetro para su elaboración la idea de utilidad para la sociedad, para el bien común.

En la construcción de la idea del bien común esbozaba elementos de su concepción de "patria", caracterizada entonces por un sentido distinto al adoptado posteriormente. Se trataba de la idea de una comunidad, a la que todos deberían contribuir con su trabajo, tratando de conocer y de alcanzar todo lo que les es propio. Aunque fuese un concepto de nacionalidad aún incipiente, ya manifestaba un fuerte sentimiento y conciencia en esta dirección, al afirmar el significado del dominio efectivo sobre las tierras brasileñas y la relevancia de la comprensión de la especificidad de estas mismas tierras.

${ }^{18}$ Câmara, "Memória", 1813, pp. 39-40. 
El conocimiento de la naturaleza brasileña promovía el enriquecimiento del país a través de los resultados derivados de la explotación de cultivos, que no sólo prometía grandes lucros, valorización de las tierras y de los puertos, sino que también significaba la oportunidad de trabajo para muchos. Importaba en su evaluación que estas metas se alcanzaran rápida y decididamente en beneficio de la "nación" para proveerla, aumentar su comercio y favorecer a toda su población. A esta idea de crecimiento económico estaba agregada la de autonomía económica:

Cuido que de esta manera se verá en poco tiempo el Brasil más enriquecido $e$ independiente que las otras partes del mundo en lo que respecta a las producciones que la naturaleza esparció por todas; juntémoslas y apropiémonoslas; y si a esto se agrega además la industria de manufacturas, al menos las bastantes para nuestro consumo (lo que es mucho de esperar de nuestro sabio ministerio) equé imperio habrá en el mundo igual a éste? ${ }^{19}$

La preocupación con la información, característica en la trayectoria de Arruda da Câmara, presentaba asimismo otra dimensión que no es la científica, la información de las ideas políticas en boga en el viejo continente. En este sentido, a su regreso a Brasil en 1798 traza un proyecto político, el cual según declaraciones de la época, ${ }^{20}$ sería el de buscar los medios para implantar el sistema republicano en Brasil. La preocupación política le habría

19 Câmara, "Dissertação", 1982, p. 204.

${ }^{20}$ En Herson, Cristaâs, 1996, p. 278. llevado a crear, ${ }^{21}$ en esta ocasión, una sociedad política y secreta, denominada Aerópago de Itambé. Destinada a "volver conocido en Brasil el estado actual de Europa",22 el Aerópago funcionaba como un aparato informativo en el que se discutían las ideas europeas de mayor expresión a través de la lectura de libros y periódicos. De esta manera, se difundían las noticias relativas a los principales acontecimientos políticos europeos, especialmente los de influencia libertaria.

El médico Jacinto José da Silva Quintão (Río de Janeiro, Brasil, 1750-1827) defendía la idea de la necesidad de emprender medidas que propiciasen la producción de conocimientos científicos útiles para la sociedad. En este sentido, participó efectivamente en la Sociedad Literaria de Río de Janeiro y fue apresado junto con otros miembros con motivo de la indagación ordenada por el conde de Resende.

A Da Silva le preocupaba el conocimiento y la clasificación de las especies vegetales brasileñas $y$, principalmente, la introducción y el perfeccionamiento de cultivos interesantes económicamente como el de la cochinilla. Así pues, en su producción se desta$\operatorname{can}^{23}$ la "Classificacão de plantas brasileiras" y la "Memória sobre a cochonilha e o método de a propagar, oferecida aos lavradores brasileiros, por um

\footnotetext{
${ }^{21}$ Existen algunas controversias en cuanto a la creación del Aerópago. Véase Câmara, $M a$ nuel, 1982 , p. 59 .

${ }^{22}$ Manuel Arruda da Câmara citado en Tavares, História, 1917, p. XXIV.

${ }^{23}$ Los registros de sus producciones, desafortunadamente, son escasos.
} 
patriota zeloso e amante da felicidades pública". ${ }^{24}$

La posibilidad de alcanzar una cierta autonomía económica con el desarrollo de ciertas actividades, como las dedicadas a los nuevos cultivos, era en su opinión una invitación a su adopción. Imbuido de estas ideas, dedicaba sus estudios a los "brasileños", reconociéndose como un "patriota celoso".

En esta perspectiva, comprendía el estudio de los recursos naturales existentes en las tierras brasileñas como de gran utilidad para la promoción del país. Entre los diversos cultivos, el de la cochinilla ${ }^{25}$ le mereció mucha atención, disertando sobre sus características, su método, sus técnicas y su importancia económica.

El interés por la cochinilla, ${ }^{26}$ así como también por el cultivo del añil, se derivaba en parte del significado económico de esta rama del comercio, tintes de lujo, que se encontraba en ascenso en el mercado.

El conocimiento de las facilidades de su cultivo y de las ventajas económicas propias de esta actividad eran, en su opinión, una invitación a su adopción a favor del crecimiento de Brasil.

Este ejemplo [de México] deben seguir nuestros labradores si quieren ser útiles

${ }^{24}$ O Patriota, núm. 4, octubre de 1813, pp. 11-19.

${ }^{25}$ Ibid.

${ }^{26}$ La cochinilla era un insecto que se colocaba en diversos arbustos que le servían como fuente de alimentación y lugar para la colocación de huevos. En el proceso de metamorfosis, con la creación de los capullos, se iniciaba la producción del "jugo" de color rojo, base para la producción del colorante. a sí mismos y a la patria, puesto que no puede haber una planta de menos trabajo y más lucrativa a la que cualquier terreno sirve y que pueda servir mejor de heredad, y que no le sea necesaria tanta esclavitud para hacer una fortuna perenne. [...] Yo invito a mis compatriotas labriegos a plantar grandes rocadas de cardos para criar y recolectar grandes sumas de cochinilla, cuyo trabajo de buen provecho no os pondrá dificultades para otras plantaciones de uso común, porque para la cochinilla no se necesita tanta esclavitud para extraer lucro. ${ }^{27}$

Se preocupaba de modo relevante por la producción de conocimientos útiles y, con la divulgación de los mismos, de la promoción de la sociedad brasileña. Se expresó de esta forma en su estudio sobre el cultivo de la cochinilla:

Dedicatoria. ¿A quién con más satisfacción podría yo comunicar mis observaciones que a vos? Es la cochinilla este ramo útil del comercio que tuvo su principio en este nuestro país en el virreinato del excelentísimo marqués de Lavradio, y después en el del excelentísimo Luis de Vasconcelos e Souza, que hicieron cuanto pudieron para introducir y elevar en este país al mayor auge su cultivo: pero la falta de los verdaderos conocimientos sobre esta materia fue la causa de no haber visto realizados sus loables trabajos y deseos; porque el errado método, que os fue enseñado, de en tal caso propagar la cochinilla tirando parte de los vermes de unos cardos y poniéndoselos a otros, no os ha producido su deseada

${ }^{27}$ O Patriota, núm. 4, octubre de 1813, pp. $17 \cdot 18$ 


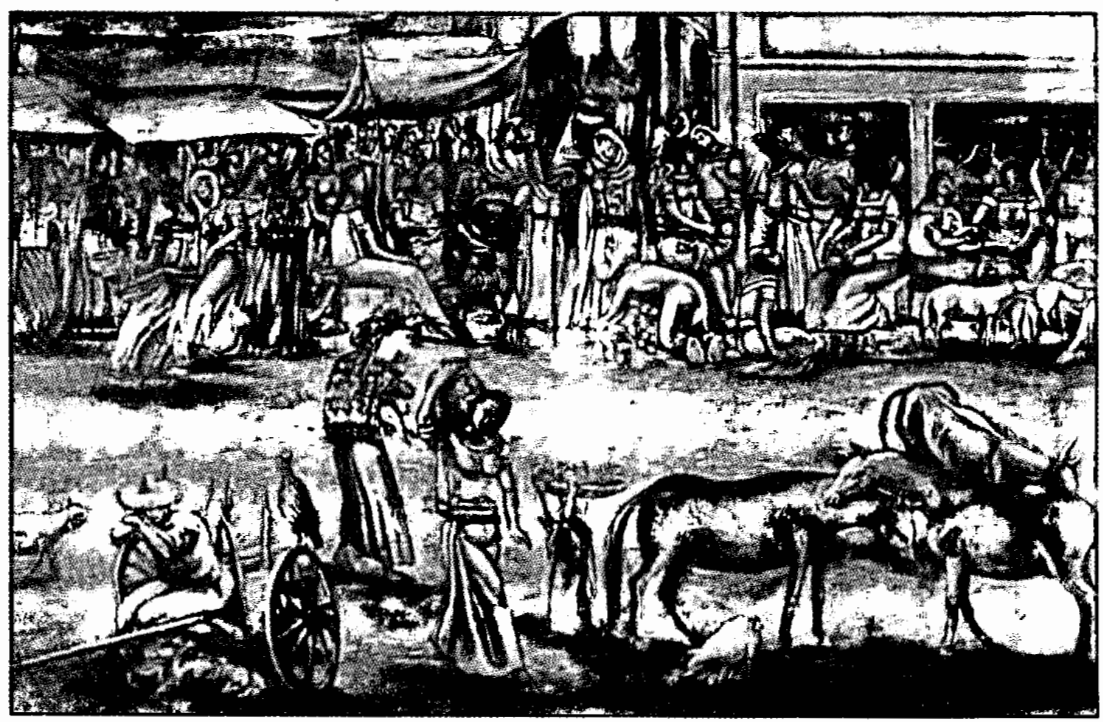

propagación, os dio causa de ser totalmente abandonado este cultivo, para el que es tan propio este clima: sin embargo, animado yo, y esperanzado en los deseos que tengo de ser útil a vos y al Estado, quiero participaros las verdaderas luces que he adquirido sobre este objeto, dándoos un método de propagarlas para que seáis útil a vos mismo y promováis la felicidad de la patria mía y vuestra, y de la nación entera, y de tener yo la satisfacción de ver aceptado y puesto en práctica mi trabajo por mis compatriotas celosos, y agradecido, $y$ agradecidos a las riquezas de la omnipotente naturaleza, juzgándome ser el primero que con tanta individuación os haga conocer la cochinilla y su propagación. ${ }^{28}$

${ }^{28}$ Ibid., pp. 11-12.
La preocupación por el conocimiento en favor del bienestar de la población y por su progreso fundamentaron su trayectoria y lo configuraron como un "patriota celoso". 29

\section{CONSIDERACIONES FINALES}

Los ilustrados aquí retratados comprendían como una misión la búsqueda del conocimiento de la naturaleza que los rodeaba, del reconocimiento de la aptitud y de la capacidad intelectual de sus habitantes. La plenitud de esta misión representaba un camino para la creación y afirmación de la conciencia de la "nacionalidad".

${ }^{29}$ lbid., p. 11. 
Es importante afirmar que a los términos "nación" y "patria" les fueron conferidos varios sentidos, cambiando su contenido semántico conforme a la época y al espacio en el cual se insertaban. En la América española, estos conceptos pasaron por diferentes etapas, siendo inicialmente comprendidos a partir de la afirmación de su hispanidad, de la pretensión de ser iguales a los españoles de España. Con el impacto de la revolución estadunidense, la comprensión se amplía y la "nación" se configura contemplando a toda América. Posteriormente, se esboza el sentimiento de pertenencia a un suelo distinto que ya no es el español ni el continente americano como un todo.

La inclusión de estos conceptos en el pensamiento de los ilustrados criollos en el momento de un "Patriotismo arqueológico" 30 no representaba aún el deseo de integrar a la población indígena en aquel organismo social, sino, primordialmente, la necesidad de afirmarse distinguiéndose de los españoles. La "patria" comprendía algunos segmentos sociales, o mejor, era la "nación" blanca. En esta misma perspectiva se insertaba la sustitución del término criollo por americano, connotación que ampliaba el sentido etnográfico con matices políticos, culturales y económicos, es decir, como un grupo con intereses, cultura y sentimientos definidos.

En los escritos de estos ilustrados eran frecuentes expresiones como "nuestra nación", "nuestra América", "patriotas americanos", "bien común de la patria", "brasileños", "patricios", que

${ }^{30}$ Minguet, "Concepto", 1973, p. 64. esbozaban la configuración de un sentimiento de que aquellas tierras, Nueva España y Brasil, no sólo eran territorios en contraposición a España y a Portugal, sino también comunidades que iniciaban los pasos en dirección a una "patria". Las cuestiones que trataban estos ilustrados tenían su origen, según sus propias palabras, en el "honor que se debe a la patria y a la nación". ${ }^{31}$

Todo ello representaba el esfuerzo de delimitación de diferencias y de afirmación de valores propios, de la construcción de una conciencia, aunque aún en su forma embrionaria y particularizada. La idea de "patria" concebida entonces no incorporaba a todos los segmentos sociales, sino que se trataba de una idea embrionaria y circunscrita.

Aunque estos conceptos presentaban estas limitaciones, no queda duda en cuanto a su significado en el proceso de concientización de la comunidad que se imaginaba formar. Las concepciones y reflexiones de los ilustrados los configuraban como hombres de ciencia que buscaban el enfrentamiento de circunstancias de la época y no como "filósofos de gabinete", hombres distanciados de la vida, como ironizaba Alzate.

La afirmación de los recursos naturales y de sus especificidades, de los valores culturales y de la capacitación del "brasileño" y del "mexicano" contribuían a la cristalización de una cultura autóctona y a la formación de una "mexicanidad" y de una "brasileñidad". Los ilustrados, a través de sus trayectorias, desarrollaron esa conciencia y "presintieron" el surgimiento de una

${ }^{31}$ Alzate y Ramírez, "Historia", 1831, p. 5. 
"patria". En este sentido, las primeras referencias a las denominaciones futuras de estos territorios, como Brasil y México, manifestaban el presentimiento de un distanciamiento de lo que representaban hasta entonces las metrópolis España y Portugal.

En la comprensión que los ilustrados tenían de la "patria", la naturaleza de América era diferente, peculiar, propia, pero no inferior a las de otras partes del mundo como quería hacerlo creer el pensamiento europeo. Su peculiaridad tenía que ser reconocida y atendida en sus necesidades y, por tanto, las decisiones y las definiciones de aquellas que estaban en ultramar no eran pertinentes.

Los ilustrados buscaban el reconocimiento de su existencia diferenciada, de su capacidad intelectual, de su autonomía para usufructuar sus recursos y fuerzas, pero no una ruptura política. El proceso de autonomía se iniciaba en el campo intelectual, cultural, para después proyectarse políticamente. Las independencias políticas en la primera mitad del siglo XIX fueron resultado de un conjunto de movimientos de distintos caracteres, siendo parcial cualquier interpretación unívoca.

De esta manera no se pretende afirmar la existencia de una vinculación necesaria entre la Ilustración y los movimientos de emancipación política en las Américas. En la realidad el objetivo fue entender el pensamiento científico de los ilustrados como un factor fundamental en el proceso de toma de conciencia, como el antecedente ideológico de la entidad política que se iba a gestar. Sus ideas y posicionamientos ante los problemas y las circunstancias de la vida apuntaban a la formación de una conciencia, aún embrionaria, de la nueva entidad política que se estaba gestando. Las ideas que estos hombres abanderaron fueron realmente decisivas, como lo resaltó Francisco Falcón, ${ }^{32}$ para la formación de las generaciones de los líderes de las independencias, pero no hicieron una "revolución".

La idea de la separación política propiamente dicha aún era prematura entre los ilustrados. Para Bartolache y Alzate importaba la idea de una unidad imperial y ellos reclamaban el derecho de integrarla, o sea, Nueva España debería formar parte de la "nación" española. Por otro lado, en muchos de sus textos ambos se declaraban fieles al rey.

En el caso brasileño esta desvinculación contó con otro factor de carácter político, como la venida de la familia real y la idea de un gran imperio portugués, imprimiendo al escenario brasileño una configuración distinta a la de Nueva España. Con la presencia de la corte, la sociedad brasileña experimentó otro momento en las relaciones con la metrópoli, aunque esto no representase una señal de ruptura. De esta forma, la historia de la emancipación política de Brasil tuvo ciertas peculiaridades, como el hecho de haberse realizado a partir de un movimiento de aproximación y no de rechazo a la metrópoli. En Brasil se pasó de la situación de colonia a la constitución de un imperio, mientras que Nueva España pasó de ser una colonia a ser una nación independiente. En cada región del continente americano, los movimientos por la emancipación pre-

$$
32 \text { Falcon, "Ilustração", 1989, p. } 82 .
$$


sentaron rasgos propios y ritmos diferentes, aunque comulgasen del mismo deseo de autonomía.

Aunque el pensamiento y la trayectoria de estos científicos no presentaban propuestas de ruptura política, expresaban sin embargo un sentimiento diferenciado en relación con su condición colonial. La distinción nación/patria apuntaba a un proceso progresivo de distanciamiento, por el cual ya no se veían como portugueses o españoles. Las ideas científicas que ellos defendían, al permitir la construcción de fundamentos para el conocimiento y afirmación de los recursos y los valores (humanos, económicos) propios de su existencia, fueron elementos desencadenantes del proceso de distanciamiento, representaron un primer esfuerzo para el reconocimiento de la necesidad de autonomía económica, intelectual y política. Se establecía así la diferenciación entre Nueva España y España, entre Brasil y Portugal.

Por otro lado, a pesar de este no encadenamiento lógico entre pensamiento ilustrado y emancipación política, es interesante tener en cuenta que algunas de las manifestaciones de este pensamiento fueron comprendidas en cuanto ideas de connotación revoluciona. ria. El proceso de indagación contra la Sociedad Literaria de Río de Janeiro en 1794 , se configuró en función de supuestas actitudes de subversión del orden político. Este carácter "revolucionario" atribuido a aquella sociedad no quedó circunscrito a las páginas procesales del siglo XviI, en la medida en que la propia historiografía ${ }^{33}$ le confi-

${ }^{33}$ Costa, "Introducão", 1982, pp. 64-125. rió también una caracterización de conjuración junto con los demás movimientos llamados revolucionarios (Inconfidencia Mineira, Conjura Baiana, Conspiração de Suassuna y Revolução Pernambucana).

El conocimiento emancipaba y el ilustrado era un hombre que también buscaba su emancipación de la tradición y de la autoridad política y religiosa. Su actitud, aunque aún no era propiamente la de un revolucionario, aunque aún no pensaba en forma directa en una independencia o separación, influyó en las generaciones futuras que aspiraron y concretaron una revolución, no solamente intelectual, sino social y política. De cualquier forma, era evidente y común a todos estos ilustrados la concepción pragmática, la creencia en la razón y en la ciencia como instrumentos para el progreso de los países que se formaban.

Es importante afirmar que las ideas y los conocimientos de estos ilustrados informaron y formaron a la generación de los independentistas. Sus pensamientos llegaron a los partidarios de la emancipación a través de su estudio y de los discípulos de estos pensadores, como Miguel Hidalgo, iniciador de la independencia mexicana y que estudió con un grupo de jesuitas defensores de la naturaleza americana.

Asimismo, era importante emanciparse del pasado y de la historia que les había sido impuesta a lo largo de la colonización como la única que les confería la posibilidad de su existencia. Los contenidos y los valores difundidos durante los años de dominación colonial forjaron a los hombres latinoamericanos como seres sumisos. Era urgen- 
te una nueva actitud de enfrentamiento y transformación que destruyese argumentos y que afirmase su condición de capacitados y autónomos.

Hombres de ciencia como Alzate, Bartolache, Arruda da Câmara y Jacinto Quintão, que se dedicaron a la adopción de los nuevos conocimientos científicos para promover el conocimiento de la flora, de la fauna y de las características físicas de las tierras que habitaban, y el rescate de su pasado histórico, enfrentaban paralelamente todo aquel pensamiento que a causa de una supuesta incapacidad intelectual, fisica y moral contribuía a la perpetuación de la condición colonial de sus pueblos.

Estos hombres consagraron sus vidas y sus ideas al bien común de la patria, "a cuya construcción todos los particulares tienen la obligación de aportar sus materiales de acuerdo con sus talentos". 34

Las ideas, las actitudes y los comportamientos de estos científicos, exponían una conciencia aún difusa y un presentimiento de la nueva entidad social y política que se estaba gestando. Expresaban una nueva mentalidad latinoamericana.

\section{BIBLIOGRAFÍA}

-Alzate y Ramírez, José Antonio, Asuntos varios sobre ciencias $y$ artes. Obra periódica dedicada al rey. N.S., núm 1, Imprenta Biblioteca Mexicana del Lic. D. Joseph de Jaúregui, México, 1722.

, Diario Literario de México,

Imp. de la Biblioteca Mexicana, México, 1768.

${ }^{34}$ Câmara, Manuel, 1982, p. 114.
México, tomo I, reimpresas en la Oficina del Hospital de S. Pedro a cargo de Manuel Buen Abad, Puebla, 1831.

- "Historia de la Nueva España", Gaceta de Literatura de México. tomo I, Reimpresas en la Oficina del Hospital de S. Pedro a cargo de Manuel Buen Abad, Puebla, 1831, p. 5.

Gaceta de Literatura a la carta impresa por un pseudoregnícola", Gaceta de Literatura de México, vol. I, núm. 22 y 23, 18 de julio y 14 de agosto de 1789 en Roberto Moreno y de los Arcos, Linneo en México Las controversias sobre el sistema binario sexual 17881798, UNAM, México, 1989, pp. 112-114.

-Bartolache y Díaz de Posada, José Ignacio, Lecciones matemáticas que en la Real Universidad de México dictaba don José Ignacio Bartolacbe, primer cuaderno dedicado al excelentisimo señor don Carlos de Croix, marqués de Croix, caba. llero de la Orden de Calatrava, comendador de Molinos y Laguna Rota en la misma orden, teniente general de los Reales Ejércitos de S. M. virrey, gobernador, $y$ capitan general de Nueva España, presidente de la $R$. Audiencia de México etc., etc., México, 1769.

Mercurio Volante, con noticias importantes $y$ curiosas sobre varios asuntos de física y medicina, por don José Ignacio Bartolache, doctor médico, del Claustro de esta Real Universidad de México, 1772, Coordinación de Humanidades-UnAM, México, 1979.

-Câmara, Manuel Arruda da, "Memória sobre a cultura dos algodoeiros oferecida ao ilustríssimo e excelentíssimo senhor D. Rodrigo de Sousa Coutinho, ministro e secretário de Estado da Repartição da Marinha e Negócios Ultramarinos por Manuel Arruda da Câmara, doutor em medicina pela Universidade de Montpellier, da Academia das Ciências da mesma cidade, correspondente da Sociedade de Agricultura 
de Paris e da Academia Real das Ciências de Lisboa, e naturalista empregado no serviço de S. M. fidelíssima na Capitania de Paranambuc. Ano 1797" en Manuel Arruda da Câmara, Manuel Arruda da CâmaraObras reunidas, Fundação de Cultura Cidade do Recife, Recife, 1982, p. 253.

- "Memória sobre o algodoeiro continuada do núm. 2 pag. 43", $\mathrm{OPa}$ triota, núm. 3, marzo de 1813 , Río de Janeiro, pp. 39-46.

, "Dissertação sobre as plantas do Brasil que podem dar linhos próprios para muitos usos da sociedade, e suprir a falta do cânhamo, indagadas de ordem do príncipe regente nosso senhor por Manuel Arruda da Câmara, doutor en medicina. Rio de Janeiro: Impressao Regia, 1810", en Manuel Arruda da Câmara, $M a$ nuel Arruda da Câmara,Obras reunidas, Fundação de Cultura Cidade do Recife, Recife, 1982, p. 204.

-Costa, Emília Viotti da, "Introdução ao estudo da emancipaçāo política do Brasil" en Carlos Ghilerme Mota (comp.), Brasil em perspectiva, DIFEL, Sao Paulo, 1982, pp. 64-125.

-Falcon, Francisco José Calazans, "Da Ilustração a revolução -percursos ao longo do espaço -tempo setecentista", Acervo, vol. 4, núm. 1, enero-junio, 1989, Río de Janeiro, pp. 53-87.

-Gerbi, Antonello, La disputa del nuevo mundo. Historia de una polémica,1750. 1900 , Fondo de Cultura Económica, México, 1993.

-Herson, Bella, Cristāos-novos e seus descendentes na medicina brasileira (1500-1850), Editora da Universidade de São Paulo, São Paulo, 1996.

- "Idéias de independencia no Brasil em fins do século passado", $R e$ vista do Instituto Histórico e Geográfico Brasileiro, vol. 47, núm. 1, 1884, Río de Janeiro, pp. 127-128.
-Lyra, M. de Lourdes Viana, A utopia do poderoso império; Portugal e Brasil: bastidores da política, 1798-1822, Sette Letras, Río de Janeiro, 1994.

- Manuel Arruda da Câmara, Obras Reunidas, coligidas e com estudo btográfico por José Antonio Gonsalves de Mello, Fundação de Cultura Cidade do Recife, Recife, 1982.

-Minguet, Charles, "El concepto de nación, pueblo, Estado y patria en las generaciones de la independencia" en Jean-René Aymes et al., Recherches sur le monde bispanique au $\mathrm{XIX}$ siècle, Ed. Universitaires, París, 1973, p. 64.

-Moreno de los Arcos, Roberto, Ensayos de bistoria de la ciencia y la tecnología en México, Instituto de Investigaciones Históricas-Unam, México, 1986.

- Linneo en México. Las controversias sobre el sistema binario sexual, 1788-1798, UNAM, México, 1989.

-O'Gorman, Edmundo, A invenção da América, reflexão a respeito da estrutura bistórica do novo mundo e o sentido do seu devir, ed. Universidade Estadual Paulista, São Paulo, 1992.

-Saldaña, Juan José, "Nuevas tendencias en la historia latinoamericana de las ciencias", Cuadernos Americanos, Nueva Épo$c a$, año vII, vol. 2 , núm. 38, marzo-abril 1993, México, pp. 69-91.

-Tavares, Francisco Muniz, História da Revolução de Pernambuco de 1817, Impr. Industrial, Recife, 1917.

-Zea, Leopoldo, La filosofía como compromiso de liberación, Biblioteca Ayacucho, Caracas, 1991.

-Whitaker, Arthur P., "The dual role of Latin America in the enlightenment" en Arthur P. Whitaker, Latin America and the enlightenment, D. Appleton, Century Company, Nueva York, 1942. 